\title{
DIE IMPERIALE MILITÊRE BELEID TEN OPSIGTE VAN SUID-AFRIKA \\ (1908-1910)
}

INLEIDING

In Militaria 1/4 (1969) is, met betrekking tot die vooruniale tydperk, besonderhede verstrek aangaande 'n aantal geheime militêre konferensies wat in 1907, 1908 en 1909 in ons land gehou is, ten einde interkoloniale militêre samewerking in Suider-Afrika te probeer bevorder'.

1n 1908 het, na aanleiding van die vraag watter aandıel die Imperiale magte, in geval van oorlog, in die verdediging van Suid-Afrika moet hê, genl. lord Methuen o.m. verklaar dat omstandighede daartoe sal kan lei dat Brittanje sy troepe aan Suid-Afrika sal moet onttrek en dat in Suid-Afrika gestasioneerde Imperiale troepe slegs die Kaapse skiereiland sal verdedig².

Op 31 Mei 1910 het genl. lord Methuen, op grond van die amptelike Britse publikasie The strategical conditions of the Empire from the military point of view, die volgende beginsels in verband met die Imperiale militêre beleid geformuleer:

a. Die handhawing van die Britse ryk berus hoofsaaklik op die militêre oppergesag op see.

b. Elke deel van die Britse ryk moet voldoende troepe vir selfverdediging op die been hou.

c. Die landmagte van die onderskeie ryksdele sal dalk onder sekere omstandighede verplig wees om gesamentlik op te tree indien die voortbestaan van die Britse ryk bedreig word.

Hierdie drie beginsels is, aldus die opsteller, aan die Koloniale Konferensie van 1907 voorgelê en gunstig deur die verteenwoordigers van die onderskeie ryksdele beoordeel, terwyl sy latere briefwisseling met die onderskeie koloniale regerings, die Britse Departement van Verdediging en die opperbevelhebber van die Britse vloot op bogenoemde beginsels gebaseer is.

Vervolgens het genl. lord Methuen die militêre toestand in Suid-Afrika onder oë geneem en die vraag probeer beantwoord met watter militêre vraagstukke die jong Unie van Suid-Afrika dalk te kampe kan kry.

In hierdie bydrae word sy sienswyses ten opsigte van twee moontlikhede, t.w. (a) oorlog met sekere moondhede met uitsondering van Duitsland, en (b) oorlog met 


\title{
OORLOG MET SEKERE MOONTHEDE MET UITSONDERING VAN DUITSLAND
}

\author{
a. Oor land of vanuit die see
}

In hierdie verband verklaar genl. lord Methuen:

When we consider that in the late South African War over 440000 men were transported to South Africa by sea before the conflict was brought to a conclusion, and that troops were raised locally and fought on the British side, and when we also consider that on future occasions the whole of the South African nation, both British and Dutch, will without doubt combine to repel an invasion, we cannot but come to the conclusion that no power will include in its wars plans to attempt to establish sovereignty over the South African Union.

Aan hierdie sienswyse voeg genl. Methuen die volgende gedagte toe:

While there may possibly be a few individuals here and there who are still opposed to the British flag, there is probably not a single individual in South Africa who would not be more than opposed to the flag of any other nation.

Waar genl. lord Methuen dus van die veronderstelling uitgegaan het dat, tydens 'n oorlog met sekere moondhede, met uitsondering van Duitsland, verowering en besetting van Suid-Afrika nie die oogmerk van die aanvaller(s) sou wees nie, is deur hom wel rekening gehou met moontlike aanvalle op die Britse vlootbasis op Simonstad, die bombardering van kusstede soos Kaapstad, Oos-Londen, Durban en Port Elizabeth, en die moontlikheid van strooptogte en verwoesting van eiendom deur vyandelike militêre ekspedisiemagte.

\section{b. Die Kusverdedigingsvraagstuk}

In dié verband is deur genl. lord Methuen verklaar dat:

i. Die kusverdedigingsvraagstuk nie losstaande van vraagstukke aangaande die algemene vlootstrategie gesien kan word nie.

ii. Die aard van die militêre verdedigingsmaatreëls wat getref moet word, hang af van die geaardheid van die aanval, wat op sy beurt weer in noue verband met die Britse militêre sterkte ter see en dié van sy teenstaander of teenstanders in oorlogstyd staan.

Met betrekking tot Simonstad en Tafelbaai verklaar hy vervolgens dat sowel die vlootbasis as die baai vir verdediging ingerig is en dat die peil van die verdedigingswerke ooreenkomstig dié aanvalsoorte is wat deur gesagdraers in Engeland in dié omgewing verwag word. Hy voeg hieraan toe dat tekortkomings in dié verband van tyd tot tyd onder die aandag van die betrokke gesagdraers gebring is, maar dat die Kaapse owerheid as gevolg van geldtekort nie in staat was om sy verpligtings betreffende die verbetering van Tafelbaai na te kom nie.

Ook maak die generaal melding van 'n opvatting wat 'n tydlank geheers het, nl. dat die verdediging van Tafelbaai en Simonstad onderling afhanklik van die vlnotbeleid is omrede alleen Tafelbaai toentertyd oor 'n hawe beskik het. 
Dalk, so vervolg hy, het die Britse vloot se sienswyse na die gereedkom van 'n hawe in Simonsbaai verander en spreek hy die hoop uit dat die Unieregering, ooreenkomstig die voorbeeld wat deur ander dominiums gestel is, die kwessie van aanvaarding van die algehele verantwoordelikheid vir die verdediging van Tafelbaai sal oorweeg. Dit geld syns insiens ook vir die verdediging van ander plekke aan die kus wat nie oor vlootbasisse bekik nie. In dié verband kan Durban wat, net soos baie kusstede in die wêreld aan bombardemente vanuit die see blootgestel is, dalk oorweeg word.

Genl. lord Methuen verklaar vervolgens dat dit nog altyd die beleid van die Britse ryk was om die daarstel van kosbare vaste verdedigingswerke vir die beskerming van privaateiendom te vermy en dat uitgawes tot die verdediging van dié plekke waar oorlogsvoorrade en herstelgeriewe vir die vloot aanwesig is, beperk is. As grondslag van dié beleid moet in gedagte gehou word dat die vrye deurgang van handelskepe op see, om die onderbreking van die skeepvaart te voorkom, van meer belang is as hul veiligheid in hawens. Met verwysing na die SuidAfrikaanse goudmynbedryf lig hy sy stelling soos volg toe: Die goudmyne vereis die uitvoer van goud na ander dele van die wêreld en indien hierdie goud nie verskeep kan word nie, is dit veiliger in ' $\mathrm{n}$ stad in die binneland as aan boord van handelskepe in 'n hawe.

Net soos in die geval van Tafelbaai sal die Unieregering ook die bewapening en verdediging van Durban en ander handelshawens aan die kus deur vaste verdedigingswerke moet oorweeg, aldus die Britse opperbevelhebber in sy verslag. Hy voeg hieraan toe dat die verdediging van Durban lig is en dat hierdie hawe van ander verskil deurdat dit meer skuiling bied en oor meer plaaslike herstelgeriewe en steenkoolvoorsieningsgeriewe beskik.

Vervolgens wend die generaal, met as agtergrond die Koninklike Kommissie van 1881 se omskrywing van die pligte van die Britse vloot, 'n poging aan om die vraag te beantwoord op watter wyse strooptogte deur militêre magte afgeslaan moet word.

Uitgaande van die toenmalige taak van die Britse vloot, naamlik om 'n grootskaalse aanslag teen enige deel van die Britse ryk te voorkom, merk hy op dat Frankryk aanvanklik die enigste land was wat oor 'n oorlogsvloot beskik het wat met die Britse vloot kon meeding. Daarna het elke groot moondheid 'n sterk vloot begin opbou en onder dié veranderde omstandighede sou daar te vieel van die hulpbronne van die Britse vloot vereis word. Hierdie omstandigheid het tot die gedagte gelei dat dit, om die Britse vloot meer vryheid van beweging te gee, beter sou wees dat elke deel van die Britse ryk oor voldoende militêre magte beskik om, tydelik altans, in geval van die landing van militêre ekspedisiemagte te kan optree.

Op grond van bostaande gedagtegang is dan ook tydens die Koloniale Konferensie van 1907 'n uiteensetting van die Britse Departement van Verdediging ter tafel gelê waarin verklaar is dat Britse oorlogskepe Britse gebied nie onder alle omstandighede teen strooptogte van elders kan beskerm nie.

Om hierdie vraagstuk vir die regering van die Unie van Suid-Afrika op te los, het die militêre raadgewers van die afgevaardigdes na die Imperiale Verdedigingskonferensie van 1909 aan die Hoof van die Imperiale Generale Staf gevra watter soort teenmaatreëls met betrekking tot dergelike militêre aanslae ten opsigte van Suid-Afrika getref moet word. Tydens 'n militêre sub-konferensie het, aldus genl. lord Methuen, die Direkteur van Militêre Operasies hierdie vraag beantwoord en op grond daarvan het die Imperiale gesagdraers tot die gevolgtrekking gekom dat dit nie nodig is om voorsiening vir teenmaatreëls te tref om stropende magte van meer as 500 man af te slaan nie. 


\section{2}

\section{DIE BELEID IN VERBAND MET OORLOG MET DUITSLAND}

\section{a. Die verhouding van die Anti-Britse element}

In geval van 'n oorlog met Duitsland reken genl. lord Methuen dat die kus verdedigingsvraagstuk wel dieselfde maar van 'n ernstiger aard sal wees en dat, in hierdie geval, die vraagstuk aangaande die militêre mag wat in Duits-SuidwesAfrika aanwesig is of op die been gebring sal word, sorgvuldige oorweging verdien. Met verwysing na hierdie aangeleentheid spreek hy dan die volgende gedagte uit:

In 1908, our information led us to believe that up to that time the Germans contemplated that, if raiding forces could be sent into British territory from German South West Africa, they could be joined by large numbers of the South Africans who objected to belonging to the British Empire, and wished to throw off all allegiance to the British Crown.

Genl. lord Methuen vervolg:

Had such a policy been adopted as late as 1908 the Germans would probably have had a rude awakening, because a considerable number of Boers who had engaged in the Herero War returned from their country thoroughly dissatisfied with the conditions of life under German rule, and had spread their views among their friends on returning to British territory.

Nieteenstaande hierdie feit sou, volgens die generaal, indien ontevredenheid in die protektorate terselfdertyd aangewakker sou word, die uitwerking van dergelike strooptogte dalk gawees het dat Imperiale troepe in Suid-Afrika vasgepen sou gewees het waar hulle, in die lig van die breë strategie van 'n oorlog met Duitsland beskou, in ander dele van die wêreld dringend benodig sou gewees het.

\section{b. Die Durbanse konferensie (1908)}

In die lig van hierdie uiteensetting het genl. lord Methuen, aldus sy verslag, reeds in 1908 besluit om die verskillende Suid-Afrikaanse regerings se sienswyse te bebekom om vas te stel tot watter mate hulle bereid sou wees om, ooreenkomstig die tweede beginsel van die Koloniale Konferensie van 1907, hul eie verdediging ten opsigte van aanvallende Duitse magte te behartig.

Tydens die konferensie van koloniale verteenwoordigers wat in Oktober 1908 in Durban gehou is, het die brigadier-generaal van die Britse Generale Staf in SuidAfrika die aangeleentheid weer ter sprake gebring. Met betrekking tot die doel van hierdie besprekings verklaar genl. lord Methuen op 31 Mei 1910:

While this conference sat ostensibly to report upon the unification of the existing Colonial forces, secret instructions were received to sound the representatives on the subject of the plans of defence which had been, or could be drawn up to keep the Germans out of British territory. 
Met hierdie geheime bedoeling in gedagte moet dan ook die vertroulike instruksie van 27 September 1908 gesien word waarin, o.m., met verwysing na 'n oorlog met Duitsland, deur genl. lord Methuen gevra is om die volgende gegewens van die koloniale owerhede te verkry:

i. Die samestelling en die sterkte van die militêre magte wat aangewend word en die stelsel van bevelvoering.

ii. Die konsentrasiepunte, die troepe wat na elkeen van dié punte gestuur sal word en die tyd wat nodig is om daar aan te kom.

iii. Die hoeveelheid vervoer en die bevoorradingsbron wat deur elke troepemag benodig is.

iv. Die uitrusting, ammunisievoorrade, en die omvang van beroepe om dit aan te vul wat op die Imperiale Kommissariaat in Suid-Afrika gedoen sal word.

In dieselfde verband is verder beklemtoon dat, met uitsondering van die bestaande Imperiale garnisoen van die Kaapse skiereiland, bystand deur Imperiale troepe, veral in geval van oorlog met Duitsland, as problematies beskou moet word aangesien dit waarskynlik is dat hul dienste in ander dele van diic wêreld vereis sal word.

Ook is, in $\mathrm{n}$ skrywe van dieselfde datum, aan die koloniale regerings verduidelik dat daar ouder die gunstigste omstandighede en met uitsondering van die reeds genoemde Imperiale garnisoen van die Kaapse skiereiland, die volgende Imperiale troepe beskikbaar sal wees: Vier kavallerieregimente, een brigade Royal Horse Artillery (twee batterye), een veldtroep Royal Engineers, twee bataljons berede infanterie, twee brigades (elkeen bestaande uit drie batterye) Royal Field Artillery, een veldtelegraafkompanie Royal Engineers, twee of drie veldkompanies Royal Engineers, vyf bataljons infanterie; met die nodige mediese-, veeartsenykundige, vervoer- en bevoorradingsdienste.

Op 6 November 1908 is, nadat die Hoë Kommissaris se goedkeuring verkry is, deur genl. lord Methuen 'n geheime skrywe aan die verskillende koloniale owerhede gestuur waarin gegewens met betrekking tot beskikbare troepe en die aanwending daarvan tydens so 'n noodtoestand gevra is.

Sowel die Kaapkoloniale regering as die regering van die Oranje-rivierkolonie het, so vervolg genl. lord Methuen, geen gedetailleerde gegewens verstrek nie, maar wel het die kommandant-generaal van die Kaapse koloniale magte hom aangaande die plan ingelig wat hy persoonlik uitgewerk het. In dié plan is sekere wysigings aangebring terwyl tewens die wenslikheid van die verdediging van Kimberley beklemtoon is. Aangesien daar geen offisier van dile Kaapkoloniale magte beskikbaar was nie, is 'n offisier van die Royal Engineers, soontoe gestuur om 'n verdedigingsplan op te stel, terwyl die enigste siviele persoon wat op Kimberley in vertroue geneem is, die sekretaris van die De Beers-maatskappy was.

\section{c. Gegewens verstrek}

Na verloop van tyd het die regerings van Transvaal, Suid-Rhodesië en Natal op die skrywe van 6 November 1908 geantwoord en die benodigde informasie verstrek, maar as gevolg van die unifikasie-voorbereidings is die grondslag van die korrespondensie vertraag. Gevolglik was genl. lord Methuen eers op 10 Januarie 1910 in staat om, soos hy dit gestel het.

to report to the War Office the measures which the Colonial Governments were prepared to take to defend their own territory in the 


\section{d. 'n Verslag en voorstelle}

Die teks van hierdie verslag wat aan die Britse Minister van Verdediging gestuur is, lui soos volg:

1. With reference to my letter of 8 th March, 1909, asking for instructions about the principles upon which a plan of campaign should be drawn up for dealing with German South West Africa in the event of war with Germany, I have the honour to enclose a precis of information received from the Governments of the several South African Colonies, or from their professional advisers, on the subject of the defensive measures which they propose to take in such an emergency.

2. In a defensive plan of campaign I would propose to concentrate a Mounted Brigade of the troops under my command at De Aar, and to mobilise the remainder of the Imperial forces at their permanent stations in readiness for concentration, either to deal with the local situation, or to be despatched from South Africa under such orders as may be issued to me on the subject.

3. On receipt of further instructions as regards the availability of Imperial forces for the purpose, $I$ propose, in consultation with the Naval Commander-in-Chief, to draw up an offensive plan of campaign on the lines advocated in my despatch of 8th March, 1909.

\section{e. Die "Precis of Measures"}

Die Precis of measures that South African Governments will take in the event of war with Germany wat deur genl. lord Methuen opgestel is en van 1 Januarie 1910 dateer, bevat die volgende besonderhede:

\section{Kaapkolonie}

i. Moontlike Duitse opmarsrigtings

i. As gevolg van die waterskaarste is daar slegs drie opmarsrigtings van DuitsSuidwes-Afrika na die Kaapkolonie, t.w. oor Ramondsdrif na O'okiep, Dewetsdorp, Garies en Van Rhynsdorp; oor Schuitdrif na Kenhardt, Sakvallei en Calvinia; en oor Upington na Prieska en De Aar.

ii. Verdedigingsmaatreëls

Kaapse koloniale troepe wat op Fraserburg, Prieska en Upington gestasioneer is, sal die grens bewaak en op elkeen van dié dorpe en Clanwilliam sal dertig dae se voorrade vir 500 man en 500 perde aangehou word.

'n Mag wat saamgestel is uit boere uit die distrik Gordonia sal die landstreek tussen die poste bewaak, terwyl passe in die Lingeberg gesluit en deur plaaslike magte onder uitgesoekte koloniale offisiere bewaak word.

iii. Organisasie van mobiele kolonnes en garnisoene

Dorpswagte vir die beskerming van Upington, Prieska, Fraserburg en Clanwilliam op die been gebring word, terwyl garnisoene van die Kaapse koloniale troepe langs die spoorlyn Kaapstad-De Aar gestasioneer sal word.

Daar sal drie mobiele kolonnes gevorm word, t.w., twee wat binne tien dae saamtrek en onderskeidelik op Upington en Prieska geleër sal wees, terwyl dile derde met 'n konsentrasietyd van 12 dae oor Fraserburg, 'n plek 80 myl van Fraserburg Roadstasie, as 'n basis sal beskik. 
Ofskoon genl. lord Methuen van oordeel was dat die mobiele kolonnes veertien dae vir konsentrasie-doeleindes beskikbaar moet hê, staan hy nie verder by die aangeleentheid stil nie, maar hy vermeld wel dat elke kolonne uit 500 beredenes met twee 15 -ponder kanonne sal bestaan en volledig met vervoer, bevoorradingsopslagplekke en bevoorradingskolonnes uitgerus sal wees, terwyl elke kolonne sesen-dertig waens, met ses dae se voorrade vir soldate en perde, saamneem.

\section{iv. Plaaslike vervoerbronne}

Vervoermiddels en trekdiere sal plaaslik aangekoop word, terwyl die behoeftes vir die drie kolonnes 426 waens en 4592 muile bedra. Die plaaslike hulpbronne bestaan uit 2083 waens en 12347 muile.

v. Plaaslike voorrade

Dit word aangeneem dat elkeen van die basisse in staat sal wees om voorrade vir veertien dae aan die kolonnes en 'n maand se voorrade aan die plaaslike inwoners te verstrek.

vi. Kimberley

Met betrekking tot die belangrikheid van Kimberley verklaar genl. lord Methuen dat hierdie sentrum se strategiese betekenis na die voltooing van die spoorlyn na Bloemfontein toegeneem het en tans slegs blootgestel is aan 'n strooptog wat deur kameelruiters van Duits-Suidwes-Afrika uitgevoer mag word. Om die dorp doeltreffend te verdedig, meen die direkteure van die De Beers-maatskappy dat 'n dorpswag van 1500 person! sonder moeilikhede op die been gebring kan word en dat die Imperiale regering 'n bevelvoerder met sy staf, 'n offisier van die Royal Engineers en 1200 gewere met bybehorende ammunisie moet verstrek.

Daar is, so vervolg hy, $300 \cdot 303$ M.M.E.-gewere op Kimberley, die verdedigingsplanne berus by die Imperiale hoofkwartier (Pretoria), en die tydsduur om die verdedigingswerke op te rig, is op veertien dae bereken.

\section{Die Oranjerivierkolonie}

Volgens genl. lord Methuen het die Vrystaatse regering geen defensiewe of offensiewe militêre maatreëls getref nie.

Transvaal

i. Georganiseerde magte. Vrywilligers

Ingeval van oorlog met Duitsland sal Transvaal tot mobilisasie oorgaan en op Kimberley of elders die volgende georganiseerde vrywilligermagte saamtrek:

Konsentrasietye

\begin{tabular}{|c|c|c|c|c|c|c|}
\hline 7 dae & & & & & 14 dae & 21 dae \\
\hline Een battery 13-ponders (4) ...... & $\ldots \ldots$ & $\ldots . .$. & $\ldots . .$. & $\ldots . .$. & Idem & Idem \\
\hline Een battery 15-ponders (4) ....... & $\ldots . .$. & $\ldots \ldots$ & $\ldots . .$. & $\ldots . .$. & Idem & Idem \\
\hline 1050 berede manskappe & $\ldots \ldots$ & $\ldots \ldots$ & $\ldots \ldots$. & $\ldots \ldots$. & 1300 & 1500 \\
\hline 150 lede van die C.S.A.R.E. ...... & $\ldots \ldots$ & $\ldots \ldots$ & $\ldots \ldots$. & $\ldots . .$. & 200 & 250 \\
\hline 1300 infanteriste $\quad \ldots \ldots . . . . . . . . . .$. & $\ldots \ldots$ & $\ldots \ldots$ & $\ldots \ldots$ & $\ldots \ldots$. & 1850 & 2400 \\
\hline 400 fietsryers $\quad \ldots \ldots \ldots \ldots \ldots$ & $\ldots \ldots$ & $\ldots \ldots$ & $\ldots \ldots$. & $\ldots \ldots$. & 600 & 800 \\
\hline Een veldambulans $\quad \ldots . . . \quad \ldots . . . \quad \ldots . .$. & $\ldots \ldots$ & $\ldots \ldots$ & $\ldots \ldots$ & $\ldots . .$. & Idem & Idem \\
\hline Drie seksies van die Veeartsenyl & rundi & ige & Diens & $\ldots . .$. & Idem & Idem \\
\hline
\end{tabular}




\section{ii. Mobilisasieskemas}

Mobilisasieskemas word op datum gehou en stafoffisiere is gewaarsku. Die hoofkwartier van die Transvaal Volunteers beskik oor voldoende mobilisasie- en uitrustingsvoorrade vir $6000 \mathrm{man}$. Op die oomblik is daar geen 13ponder ammunisie in reserwe nie, maar dit word deur die Imperiale kommissariaat verstrek. In die skema is wel voorsiening vir vervoer, maar nie vir bevoorradingskolonnes e.d.m. gemaak nie.

iii. Georganiseerde polisiemag

Transvaal kon 'n volledig toegeruste berede polisiemag van 418 met 'n battery van vier kanonne en vier meksims vir diens buite die gebied mobiliseer.

iv. Die mobilisasieskema van die Polisie

Die polisiemag kan binne twee-en-sewentig uur gemobiliseer en op Pretoria saamgetrek word. In al die vervoerbehoeftes van hierdie mag kan deur die polisie en die Departement van Openbare werke voorsien word, behalwe dat 100 muile plaaslik aangekoop moet word.

Verder beskik die Transvaal Volunteers nog oor drie pantsertreine wat elkeen met 'n twaalfponder snelvuur-kanon en twee meksims bewapen en binne sewe uur beskikbaar is.

Natal

i. Verdedigingskema

Daar bestaan ' $n$ verdedingskema ten opsigte van Durban en die bestryding van vyandelike landingstroepe, terwyl aangeneem word dat die landgrense veilig is.

ii. Kolonne vir diens buitekant die grense

Indien nodig sal 'n regiment van 500 berede troepe gewerf word, terwyl 'n battery veldartillerie aanwesig is.

\section{Suid-Rhodesië}

i. Georganiseerde magte. Polisie

Daar bestaan 'n georganiseerde polisiemag van 425 wat met ses 303 meksims, veertien 450 kanonne, een $77 \mathrm{~mm}$-kanon en ses veldkanonne toegerus is.

ii. Vrywilligers

Daar is ongeveer 1600 vrywilligers wat op Bulawayo kan saamtrek, maar nie ten volle met komberse, waterbottels en ransels of rugsakke toegerus is nie.

iii. Mobiele kolonne en ander beskikbare troepe

Tydens die Johannesburgse konferensie van 1907 het Suid-Rhodesië ooreengekom om 'n troepemag van 200 man te stuur om, indien nodig, enige ander Suid-Afrikaanse kolonie by te staan.

Suid-Rhodesië kan binne drie dae 500 man op Salisbury en elders laat saamtrek en beskik verder nog oor 900 man wat kan perdry en skiet en die veld ken.

iv. Vervoer

Al die vervoer wat nodig is vir die polisie en die vrywilligers kan, met uitsondering van waterkarre, deur die regering verstrek word.

v. Wapens en ammunisie

Daar is voldoende wapens en ammunisie in die land in voorraad. Ongeveer 500 nie-blanke polisie - Matabeles en Mashonas - kan vir informasiewerk gebruik word, terwyl 3443 L.M.- en L.E.-gewere, twee-en-sewentig L.M.karabyne, twee-honderd-en-vyftig M.A.-gewere vir nie-blankes, en 640000 303-patrone in reserwe gehou word, en kwartaalliks 300000 patrone ontvang word. 


\section{3}

\section{DIE BENUTTING VAN IMPERIALE TROEPE}

Hierdie vraagstuk geniet sorgvuldige oorweging, aldus genl. lord Methuen, en allereers is pogings aangewend om meer informasie oor die verbindings tussen die Duitse en Britse gebiede te verkry aangesien die beskikbare gegewens ontoereikend was. Informasie wat in dié verband tot 11 November 1909 ontvang is, is op 9 Desember 1909 aan die Informasieafdeling in die Kaapkolonie, aan die kommandant-gineraal van die Kaapse koloniale troepe en aan die inspekteur van die Transvaal Volu'nteers gestuur om dit by hul bestaande gegewens te voeg, maar belangrike nuwe gegewens is na dié tyd nie ontvang nie.

Die beskikbare inligting is, aldus die opsteller van die verslag, nou redelik volledig, en hy voeg daaraan toe:

$A$ copy of the route book used by German officers had been obtained and a translation forwarded to the War Office on 16th May, $1910^{3}$.

\section{4 \\ GEVOLGTREKKINGS}

In sy gevolgtrekkings aangaande al hierdie vraagstukke verklaar genl. lord Methuen dat die maatreëls wat deur die koloniale gesagdraers getref is, voldoende behoort te wees om hul gebiede teen Duitse strooptogte te verseker.

Andersyds het hy die wenslikheid uitgespreek dat dit, met die oog op die unifikasie van Suid-Afrika, wenslik sal wees dat - indien die Kaapse koloniale troepe nie alleen die toestand kan baasraak nie - Imperiale troepe na De Aar gestuur moet word.

Ook beveel hy aan dat Imperiale gesagdraers die werksaamhede van kontingente wat in die ander kolonies gereed gehou word, moet koördineer omdat daar met die oog op die in wording synde Unie van Suid-Afrika — geen ander gevestigde gesag bestaan om dit te doen nie.

\section{5 OFFENSIEWE OPTREDE? PLANNE}

Genl. lord Methuen vervolg:

Looking at the matter from the South African point of view he was in favour of offensive action against the German force in South West Africa, but as such action involved naval questions, and possibly the movement of troops by sea, it was necessary to approach the War Office to ensure whether such offensive action would be sanctioned. It was also necessary to know what Imperial troops would be available for the purpose.

Op 8 Maart 1909 het genl. lord Methuen navraag omtrent hierdie vraagstuk by die War Office gedoen. 
Op 1 April 1970 is gelas om twee veldtogplanne op te stel, t.w. 'n plan waarby die hele Imperiale troepemag in Suid-Afrika ingeskakel is, en die ander met betrekking tot dié eenhede wat in Suid-Afrika aanwesig sou wees nadat 'n kavallerie- en 'n infanteriebrigade, saam met ander troepe, na elders gestuur sou wees.

Hierdie planne word nou, aldus genl. lord Methuen, deur 'n klein komitee by die Imperiale Leërhoofkwartier, Pretoria, uitgewerk, terwyl hy beoog om na die totstandkoming van die Unieregering te vra dat 'n verteenwoordiger van die Unie se Departement van Verdediging aan die bestaande komitee toegevoeg word.

Op die tydstip waarop genl. lord Methuen sy memorandum oor sy beleid van 19081910 opgestel het, dit was in Mei 1910, was daar van amptelike Britse kant nog nie besluit om gehoor te gee aan sy versoek aangaande offensiewe optrede teen Duits-Suidwes-Afrika nie.

Op 24 April 1910 het genl. lord Methuen 'n lang bespreking oor verdedigingsaangeleenthede met genl. J. C. Smuts gevoer en tydens dié onderhoud, waartydens die organisasie van die toekomstige verdediging van die Unie van Suid-Afrika ter sprake gekom het, het laasgenoemde o.m. verklaar:

He was quite clear South Africa must not only be prepared to look after herself when England might not be able to give any help, but even in the event of England by any mischange receiving a reverse at sea.

In dieselfde skrywe is verder o.m. vermeld dat genl. Smuts ook verklaar het:

Mind you we must also remember these Germans want South Africa... 


\section{$S U M M A R Y$}

In Militaria $1 / 4$ (1969) details were given concerning secret military discussions (1907-1909) held in South Africa in an attempt to promote inter-colonial military co-operation in Southern Africa.

In 1908 General Lord Methuen formulated three principles with regard to Imperial military policy for reviewing the military situation in South Africa in May, 1910 in an attempt to provide solutions concerning military problems the youthful Union of South Africa might be confronted with.

General Lord Methuen went out from the assumption that during a war with certain powers excluding Germany, the invasion and occupation of the Union of South Africa would not be the aim.

Possible attacks on Simonstown and the coastal cities as well as the possibility of military raids were not impossible. On this basis the General, inter alia, advocated the protection of the coastal cities and the defence system for Table Bay.

In addition, General Lord Methuen in 1910 worked out plans to consider a possible German military assault oniginating in German South-West Africa by employing South African and Rhodesian forces. He was personally in favour of offensive military action against the German columns but in May, 1910 no official British decision had as yet been taken with regard to his request.

The contribution concludes by giving General Smuts' view concerning South Africa's military action and the German attitude as regards the Union of South Africa.
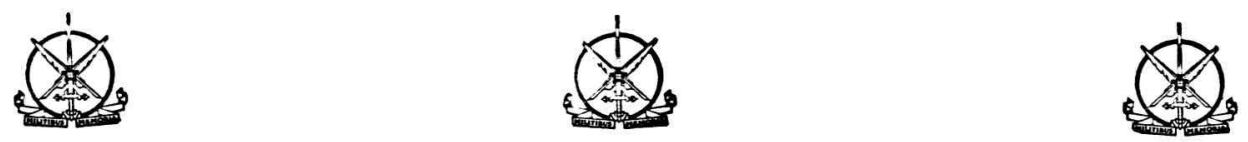

\section{AANTEKENINGE}

1. Pp. 13-14.

2. Genl. lord Methuen verwys hier na C.D.C. nr. 414 M, van 22 Desember 1909, waarın die vlootbeleid van die Britse ryk en die vereistes in verband met die kusverdediging in verskillende dele van die wêreld omskryf is en vermeld dat dié dokument op 14 Mei 1910 deur hom ontvang is.

3. In 'n voetnoot is aangeteken: Oun latest information (May, 1910) shows that there is a movement, both in German South West Africa and in the Cape Colony, in favour of connecting the railways in the respective territories. Such a connection, if made, will entirely alter the military situation.

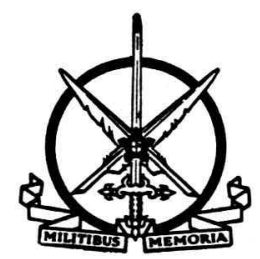

